\title{
Rancangan Virtualisasi Server Menggunakan VMWare Vsphare
}

\author{
Siti Nur Khasanah ${ }^{1}$, Sandra Jamu Kuryanti ${ }^{2}$ \\ Jurusan Sistem Informasi, STMIK Nusa Mandiri Jakarta \\ Jurusan Sistem Informasi, Universitas Bina Sarana Informatika \\ e-mail: siti.skx@nusamandiri.ac.id, sandra.sjk@bsi.ac.id
}

\begin{abstract}
A financial institution especially which have a number of customers and employees a lot, needs information and communication technology has become a major requirement, among others, in terms of information processing and information exchange. PT Bank Pundi Indonesia, Tbk has had adequate computer network infrastructure to support the needs of employees will access the data via a computer network. But the computer network infrastructure owned still not empowered optimally. Development of server virtualization technology by utilizing computer resources owned by the agency into one of the solutions to overcome these problems in lower costs incurred by the company for the purchase of physical servers and increase server performance.
\end{abstract}

Keywords-infrastructure, network, virtualization, server

Abstrak - Sebuah instansi keuangan terutama yang memiliki jumlah nasabah dan karyawan yang banyak,kebutuhan teknologi informasi dan komunikasi sudah menjadi kebutuhan utama, antara lain dalam hal pengolahan informasi dan pertukaran informasi. PT Bank Pundi Indonesia, Tbk telah memiliki infrastruktur jaringan komputer yang memadai untuk menunjang kebutuhan pegawai akan akses data melalui jaringan komputer. Akan tetapi infrastruktur jaringan komputer yang dimiliki masih belum diberdayakan secara optimal. Pengembangan teknologi virtualisasi server dengan memanfaatkan sumber daya komputer yang dimiliki oleh instansi menjadi salah satu solusi untuk mengatasi permasalahan tersebut dalam menekan biaya yang dikeluarkan perusahaan untuk pembelian server fisik dan juga meningkatkan performance server.

Kata kunci-infrastruktur, jaringan, virtualisasi, server

\section{A. PENDAHULUAN}

Kebutuhan teknologi informasi dan komunikasi sudah menjadi kebutuhan utama saat ini, antara lain dalam hal pengelolaan informasi dan pertukaran informasi. Pengembangan dan pengelolaan sistem dan teknologi informasi perlu dipersiapkan dan diterapkan sebaik mungkin agar infrastruktur tersebut dapat dimanfaatkan secara efisien dan efektif.

Hampir setiap perusahaan menggunakan teknologi informasi yang cukup kompleks, seperti penggunaan puluhan server dan berbagai alat jaringan serta komputer dengan spesifikasi hardware yang cukup tinggi yang bertujuan untuk menjamin kestabilan dan performance sistem yang handal.

PT. Bank Pundi Indonesia merupakan perusahaan keuangan yang telah memiliki infrastruktur jaringan komputer yang memadai untuk menunjang kebutuhan pegawai dalam mengakses data melalui jaringan komputer.
Akan tetapi sumber daya perangkat keras yang disediakan oleh mesin-mesin tersebut belum digunakan secara optimal sehingga penambahan mesin-mesin baru merupakan langkah yang tidak efisien sehingga digunakan sistem operasi virtualisasi untuk merancang prototype server virtual untuk meminimalisir maintenance dan anggaran untuk pengadaan hardware ((Suryono \& Afif, 2012). Dalam penelitian

Menurut (Arfriandi, 2012) Banyak perusahaan yang menggunakan processor dengan inti lebih dari satu, akan tetapi belum semua yang dapat memanfaatkan secara optimal. Dengan melihat potensi processor yang mempunyai inti lebih dari satu tersebut, kita dapat memanfaatkannya untuk menjalankan aplikasi-aplikasi dan services secara bersamaan menggunakan teknik virtualisasi pada komputer server. Konsep cluster high availability yang terdapat pada virtualisasi server dapat mengurangi 
biaya dan menyederhanakan pengelolaan pelayanan teknologi informasi.

Berdasarkan

penelitian-penelitian sebelumnya, karena permalasahan yang diteliti sama maka pada penelitian ini dibuat teknologi virtualisasi server.

\section{B. TINJAUAN PUSTAKA}

\section{Virtualisasi}

Menurut (Oktavianus, 2013) virtualisasi adalah sebuah teknik atau cara untuk membuat sesuatu dalam bentuk abstrak/virtual.

Sedangkan menurut (Arfriandi, 2012) Virtualisasi atau virtualization adalah sebuah teknik atau cara untuk membuat sesuatu dalam bentuk virtualisasi, tidak seperti kenyataan yang ada. Virtualisasi juga digunakan untuk mengemulasikan perangkat fisik komputer, dengan cara membuatnya seolah-olah perangkat tersebut tidak ada (disembunyikan) atau bahkan menciptakan perangkat yang tidak ada menjadi ada.

\section{Teknologi virtualisasi server}

Menurut (Adi, Nurhayati, \& Widianto, 2016) Pengertian virtualisasi dalam komputasi mengacu pada abstraksi dari komponen fisik menjadi objek logis. Dengan virtualisasi, dapat diperoleh utilitas yang lebih besar dari komponen fisik menjadi objek logis. Teknologi virtualisasi mengemulasi sumber daya komputasi fisik, seperti komputer desktop dan server, processor dan memori, sistem penyimpanan dan jaringan. Virtualisasi server menciptakan lingkungan virtual yang memungkinkan beberapa beban aplikasi atau server yang berjalan di satu komputer seolah-olah berjalan di komputer yang berbeda.

\section{VMWare vSphere}

VMWare vSphere adalah sebuah platform virtualisasi yang digunakan sebagai platform virtualisasi berbagai macam piranti khususnya yang terkait dengan piranti server. Virtualisasi di sini artinya bahwa sebuah piranti fisik, yang biasa kita lihat sebagai bentuk sebuah server atau yang terkait dengannya dapat dipecah menjadi beberapa piranti virtual yang masing-masing-masing berdiri sendiri dan mempunyai fungsionalitasnya masing-masing.

\section{METODE PENELITIAN}

a) Analisa Kebutuhan
Analisa penelitian dilakukan dengan beberapa tahapan yaitu:

1) Analisa Kebutuhan, merupakan langkah awal untuk menentukan perangkat yang dibutuhkan. Dalam perancangan virtualisasi server ini, dianalisa kebutuhan sesuai dengan seberapa jauh perusahaan menginginkan peningkatan performance server tanpa biaya tambahan yang besar dan kompleksitas dari perkabelan jaringan.

2) Desain, Setelah tahap analisa kebutuhan selesai, maka tahap berikutnya adalah tahap desain. Tahap desain mempunyai tujuan untuk memenuh kebutuhan pemakai sistem untuk memberikan gambaran yang jelas dan rancang bangun yang lengkap.

3) Testing, pada tahap testing dilakukan verifikasi, validasi untuk mendeteksi terjadinya error.

4) Implementasi, tahap implementasi yaitu menerapkan rencana implementasi, melakukan kegiatan implementasi dari rancangan yang sudah dibangun dan tindaklanjutnya.

b) Metode Pengumpulan Data

1) Observasi, merupakan teknik pengumpulan data dengan melakukan peninjauan langsung dan mengamati secara langsung kegiatan-kegiatan yang dilakukan oleh Pegawai Perusahaan tempat penelitian (PT. Bank Pundi Indonesia, Tbk)

2) Wawancara, merupakan teknik pengumpulan data dengan mengadakan tanya jawab secara langsung dengan pegawai PT. Bank Pundi Indonesia.

3) Studi Pustaka, pengumpulan data dengan cara mengumpulkan literatur, jurnal maupun buku berkaitan dengan penelitian

\section{HASIL DAN PEMBAHASAN \\ 1. Analisa Jaringan Berjalan}

PT. Bank Pundi Indonesia, Tbk menggunakan topologi star yang dimana setiap kantor cabang terhubung dan terpusat pada kantor pusat di jakarta. Setiap router akan terhubung secara point to point dengan modem milik Telkom, maka dari Kantor cabang terhubung langsung ke Telkom dan menggunakan cloud metro milik telkom sebagai media transmisi agar dapat saling terhubung dan berpusat pada kantor pusat di jakarta. 
Untuk terhubung antar kantor cabang, kantor wilayah dan kantor pusat, bank Pundi menggunakan sarana komunikasi transponder pada satelit. Bank Pundi menggunakan jaringan telekomunikasi pribadi guna menambah keyakinan pada keamanan dan kehandalan dalam beroperasi.

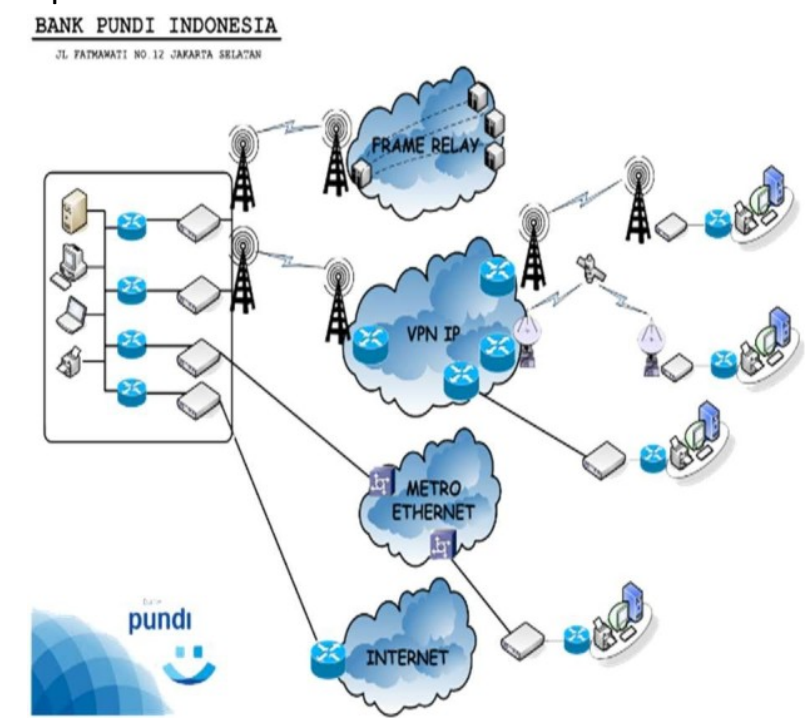

Gambar IV.1. Sarana Komunikasi data PT. Bank Pundi Indonesia,

Tbk

\section{Jaringan Usulan}

Jaringan usulan yang dihasilkan pada penelitian ini sebagai berikut:

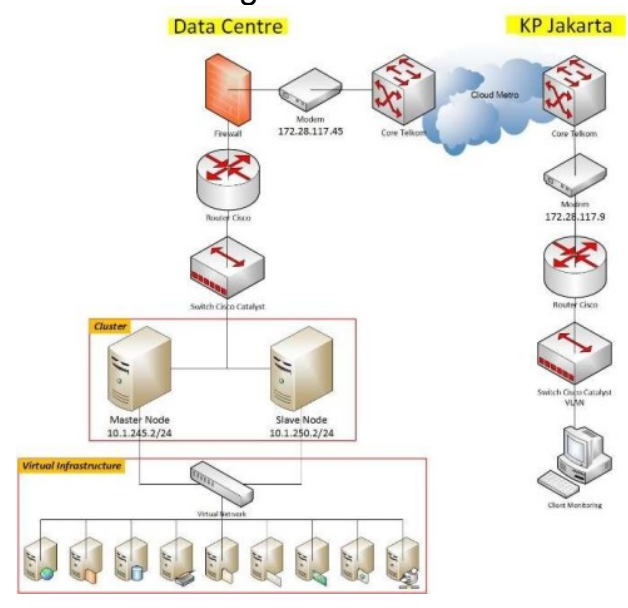

Gambar IV.2. Topologi Jaringan Usulan Kantor Pusat (Jakarta) ke Data Centre

Gambar topologi diatas adalah jaringan penghubung dari server ke client monitoring (Divisi IT). Aplikasi-aplikasi server semua terpusat atau berada pada master server dan slave server yang saling terhubung menggunakan switch. Dari switch akan tersambung langsung secara peer to peer dengan router, router langsung ke modem dan dari modem langsung terhubung ke core provider dan saling terhubung dengan cloud metro. Untung melakukan monitoring atau konfigurasi server semua dapat dilakukan langsung oleh client monitoring tanpa harus pergi ke data centre.

\section{Rancangan Aplikasi}

Untuk membangun atau membentuk virtualisasi server yang menggunakan VMare sVphere maka langkah yang harus dilakukan adalah:

a) Instalasi ESXi Server

b) Konfigurasi Sistem ESXi Server

Setelah ESXi server selesai terinstall maka kita harus melakukan beberapa konfigurasi agar ESXi server dapat digunakan seperti merubah alamat IP ESXi dari pengaturan default (DHCP) menjadi IP static. Pada konfigurasi sistem juga bisa merubah password admin, merestart, test ping, troubleshooting ESXi server, melihat log sistem dan bahkan ada opsi untuk mengembalikan pengaturan seperti semula.

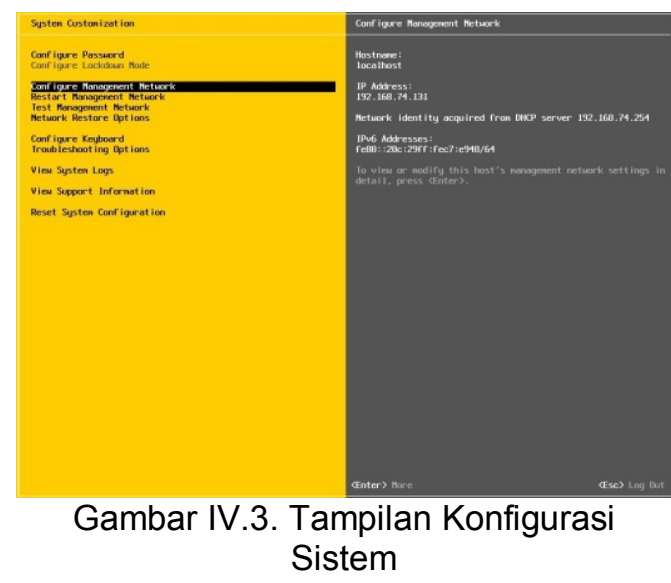

c) Instalasi Vmware vSphere Client

Setelah sistem selesai di konfigurasi maka buka IP address Vmware ESXi server di browser dengan format http://192.168.74.131 


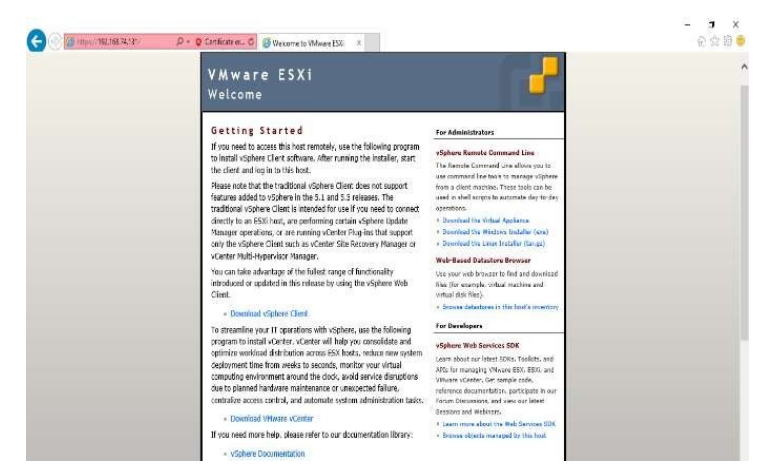

Gambar IV.4. Tampilan web ESXi server

d) Membuat Virtual Machine (Virtual Server) Setelah VMware vSphere Client terinstal langkah selanjutnya adalah membuat Virtual Machine yang didalamnya merupakan Virtual Server.

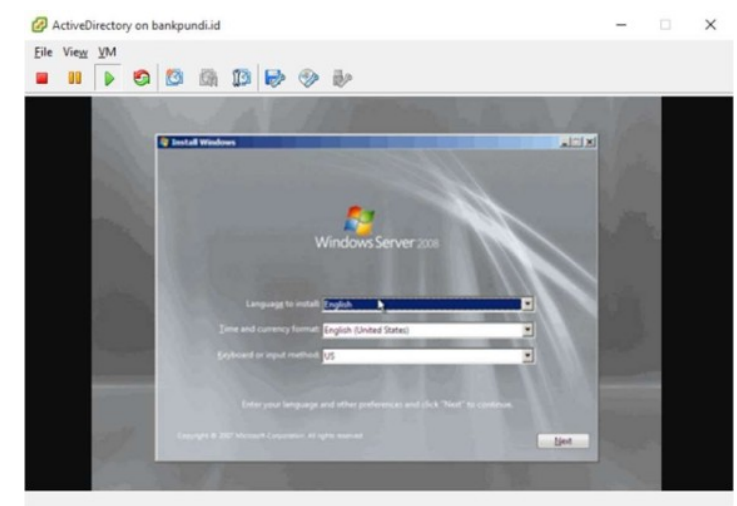

Gambar 5. Tampilan Virtual Machine

e) Backup dan Restore Virtual Machine Ketika semua proses pembuatan selesai dan virtual machine atau virtual server telah berjalan maka kita perlu melakukan backup template virtual machine agar ketika terjadi masalah pada virtual machine atau membuat virtual machine baru kita hanya perlu merestore saja sehingga bisa seperti virtual machine yang sebelumnya.

\section{Pengujian Jaringan}

\section{A. Pengujian Jaringan Awal}

Pengujian jaringan awal dilakukan dengan memonitoring jaringan dari proses kerja Processor, memory dan network yang dilakukan ketika mesian server yang ada didalam VMware Vsphere belum di aktifkan.
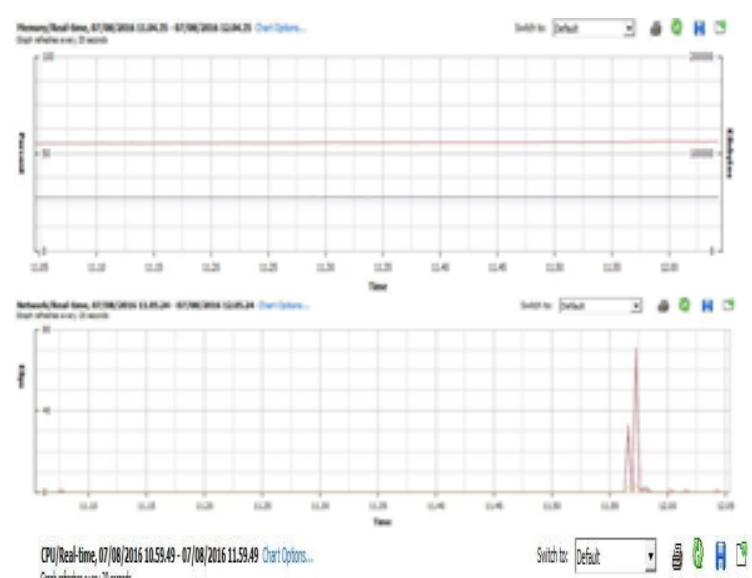

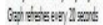

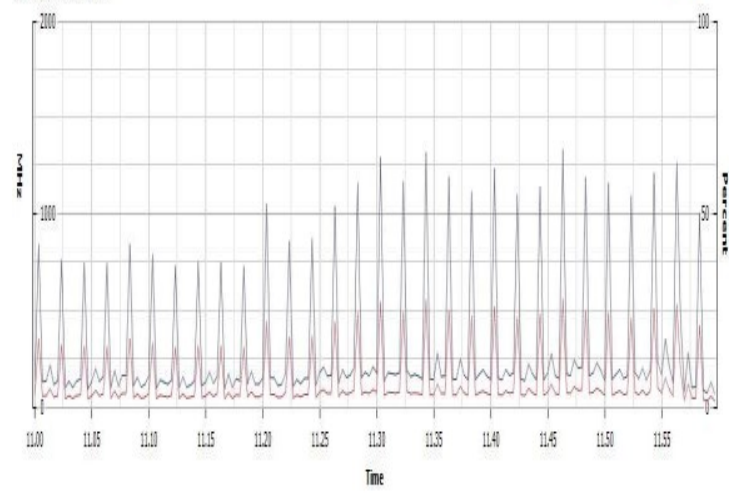

Gambar IV.6. Usage Processor, Memory dan Network

Proses kerja processor dari jam 11:00 sampai dengan jam 12:00 rata-rata kinerja processor $65 \mathrm{MHz}(1,36 \%)$ dalam keadaan idle dan $1335 \mathrm{MHz}(27,89 \%)$ dalam keadaan aktif. Untuk penggunaan memory rata-rata 107,98 Megabytes $(27,39 \%)$ dan 110.11 Megabytes $(27,63 \%)$ dalam keadaan aktif. Sedangkan untuk network pengiriman data $66 \mathrm{KBps}$, penerimaan data $4 \mathrm{KBps}$ dan penggunaan rata-rata $71 \mathrm{KBps}$.

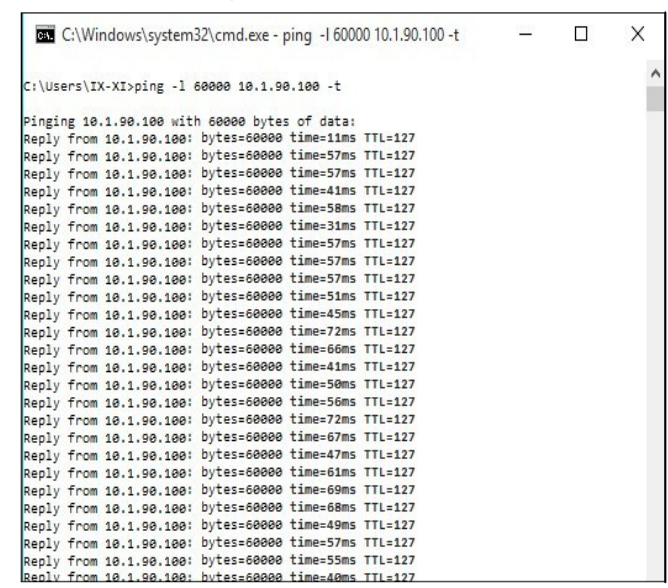

Gambar IV.7. Test koneksi (ping) ke Server Fisik 
Pengujian test ping ke server ESXi yang dibebani packet sebesar 60000 bytes, waktu yang dibutuhkan oleh packet yang dikirim dan di umpan balik untuk mengonfirmasi ke penerima rata-rata $54 \mathrm{~ms}$ dan penanda waktu packet pengiriman ping bernilai 127 .

\section{B. Pengujian Jaringan Akhir}

Pengujian jaringan akhir dilakukan ketika server virtual yang ada didalam VMware vSphere diaktifkan, kemudian dilakukan test ping ke server ESXi-host.

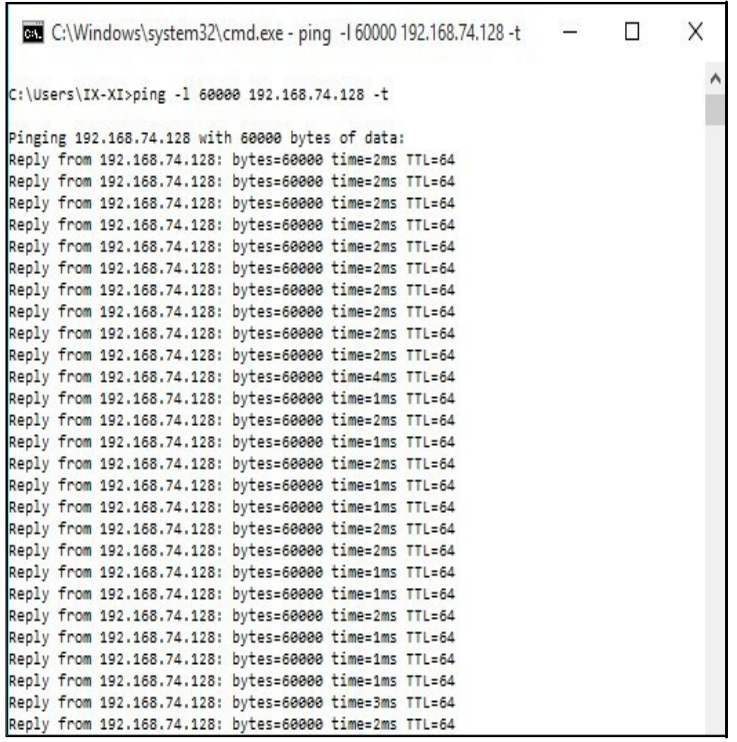

Gambar IV.8. Test konektivitas ke Virtual Server ESXi-host

\section{E. KESIMPULAN}

Berdasarkan hasil pembahasan dan penelitian yang sudah dilakukan, kesimpulan yang diperoleh adalah:

1. Penggunaan teknologi virtualisasi server dapat mengurangi yang sangat besar untuk membeli perangkat keras (hardware) untuk membangun server

2. Penggunaan virtualisasi server lebih optimal karena dengan teknologi ini kita bisa menjalankan lebih dari satu sistem sistem operasi secara bersamaan dengan fungsi yang berbeda pada setiap sistem operasi.

3. Penerapan virtualisasi server akan mempermudah proses maintenance dan recovery karena hanya berfokus pada satu server saja.

\section{DAFTAR PUSTAKA}

[1] Adi, Y. R., Nurhayati, O. D., \& Widianto, E. D. (2016). Perancangan Sistem Cluster Server untuk Jaminan Ketersediaan Layanan Tinggi pada Lingkungan Virtual. Jurnal Nasional Teknik Elektro Dan Teknologi Informasi (JNTETI), https://doi.org/10.22146/jnteti.v5i2.228

[2] Arfriandi. (2012). Perancangan, implementasi, dan Analisis Kinerja Virtualisasi Menggunakan Proxmox Esx, Vmware dan Openstack. Jurnal Teknologi, 5 nomor 2, 182-191. https://doi.org/10.1016/j.matdes.2011.11. 021

[3] Oktavianus, Y. L. (2013). Membangun Sistem Cloud Computing dengan Implementasi Load Balancing dan Pengujian Algoritma Penjadwalan Linux Virtual Server pada FTP Server. Jurnal Nasional Teknik Elektro, (1), 25-30. https://doi.org/http://dx.doi.org/10.20449/j nte.v2i1.94

[4] Suryono, T., \& Afif, M. F. (2012). Pembuatan Prototype Virtual Server Menggunakan Proxmox Ve Untuk Optimalisasi Resource Hardware Di. IJNS-Indonesian Journal on Networking and Security, 1(November), 1-5. 